\title{
Quantitative assessment of early brain damage in a rat model of focal cerebral ischaemia
}

\author{
K A OSBORNE, T SHIGENO, ANNE MARIE BALARSKY, I FORD, J MCCULLOCH, \\ G M TEASDALE, D I GRAHAM
}

From the Wellcome Surgical Institute, University of Glasgow, Glasgow, Scotland, UK

SUMMARY A method for the volumetric assessment of early cerebral infarction, together with its statistical and biological validation, is described. In halothane anaesthetised rats the stem of the right middle cerebral artery was occluded and 3 hours later (with full monitoring of respiratory and cardiovascular status) the animals were killed by perfusion fixation. In normotensive normocapnic animals the volume of infarction was $52 \pm 4 \mathrm{~mm}^{3}$ in the cerebral cortex and $21 \pm 1 \mathrm{~mm}^{3}$ in the corpus striatum. The reproducibility of the volumetric assessment was found to be excellent (coefficient of correlation 0.995 on 18 replicate measurements). The minimum number of stereotactic levels which must be assessed to yield accurate volumetric measurements of infarction is 8 . The method is sensitive at detecting alterations in the amount of infarction. For example, it can readily detect the increase in amount of structural damage in cerebral cortex following a transient episode of hypotension. This approach allows an objective assessment of drug therapy and management strategies in the treatment of cerebral infarction.

Numerous attempts have been made to produce experimentally an ischaemic lesion resembling that seen in man. One of the most commonly used methods has been to occlude the middle cerebral artery in various experimental animals ${ }^{1-6}$ in the belief that proximal occlusion of this artery is equivalent to a large focal cerebral infarct in man.

We have developed a technique for occluding the middle cerebral artery (MCA) in the rat ${ }^{7}$ which has proved useful for correlating local cerebral blood flow $^{8}$ and dysfunction of the blood-brain barrier ${ }^{9}$ with histological evidence of ischaemic brain damage. ${ }^{10}$

In this paper we detail a rigorous means for measuring the volume of early cerebral infarction in the rat after occlusion of the middle cerebral artery. This method, with its statistical validation, together with a demonstration of its ability to measure changes in the amount of structural damage in various experimental conditions, is described. Some of this data has appeared previously in abstract form. ${ }^{11}$

\footnotetext{
Address for reprint requests: Professor DI Graham, University Department of Neuropathology, Institute of Neurological Sciences, Southern General Hospital, Glasgow G51 4TF, Scotland, UK.
}

Received 3 April 1986.

Accepted 15 May 1986

\section{Materials and methods}

\section{General preparation}

Thirteen adult male Sprague Dawley rats (weighing between $320-415 \mathrm{~g}$ each) were anaesthetised and ventilated mechanically with a nitrous oxide/oxygen mixture (70\%:30\%) and, during the surgical procedures, $2 \%$ halothane. Polyethylene catheters were inserted into both femoral arteries and veins to allow the continuous monitoring of blood pressure, repeated sampling of arterial blood and the administration of drugs. The body temperature was monitored by a rectal thermometer and the animals were maintained at normothermia by external heating.

In normotensive animals, if there was a transient reduction in mean arterial blood pressure below $80 \mathrm{~mm} \mathrm{Hg}$ for more than two minutes during the observation period of 3-4 hours after occlusion of the MCA, the animals were not processed for inclusion in the study.

\section{Operative procedure}

The proximal portion of the MCA was occluded permanently under halothane anaesthesia by a modification of the microsurgical technique developed in our laboratories. ${ }^{7}$ After partial removal of the temporalis muscle but without removing the zygomatic arch, the animals underwent a left subtemporal craniectomy. The position of the skull opening was critical, and its centre was about $3 \mathrm{~mm}$ anterior and $1 \mathrm{~mm}$ lateral to the foramen ovale. The dura was opened through a cruciate incision by means of a fine needle. The MCA ran forwards initially, then turned laterally over the lateral edge of the olfactory tract. It was distinguished from 
its accompanying vein by being straighter and usually having fewer branches. The arachnoid on either side of the artery was divided by a fine needle. The stem of the MCA was coagulated just medial to the olfactory tract ${ }^{12}$ and was cut to assure the completeness of the vascular occlusion. After the surgery, anaesthesia was maintained with $0.5 \%$ halothane. The finding in the present study that a reproducible ischaemic lesion invariably developed in the territory of the occluded MCA has been substantiated by experience gained both in Glasgow and in other centres (Tokyo, Copenhagen).

\section{Groups of animals studied}

The experiments were designed to determine the ability of the method of quantification to detect an alteration in the amount of structural damage.

A group of nine animals (normotensive) was maintained normotensive, normoxic normocapnic and normothermic throughout the 3-4 hour post-operative period prior to perfusion fixation.

In a second group of seven animals (hypotensive) 15 minutes after occluding the MCA mean arterial pressure was lowered rapidly to $60 \mathrm{~mm} \mathrm{Hg}$ by the controlled withdrawal of arterial blood and maintained at this level for 30 minutes before arterial blood pressure was restored to normotensive levels. A value of $60 \mathrm{~mm} \mathrm{Hg}$ was chosen in order that normal levels of perfusion would be maintained in the areas of brain with intact autoregulation. ${ }^{13}$ After 3-4 hours the animals were perfusion fixed.

\section{Neuropathology}

The animals were perfusion fixed with FAM ( $40 \%$ formaldehyde, glacial acetic acid, methanol, 1:8:8 v/v) 3-4 hours after occlusion of the middle cerebral artery. The animals were deeply anaesthetised ( $2 \%$ halothane), heparinised and placed supine so that the thorax could be opened through a midline incision. A cannula was inserted into the ascending aorta via the left ventricle. After incising the right atrium, physiological saline was infused for $20-30 \mathrm{~s}$ at the animals' mean arterial blood pressure until the perfusate from the right atrium was bloodless. This was followed by perfusion with $150-200 \mathrm{ml}$ of FAM at the same pressure. The animals were decapitated after perfusion and the head was stored in FAM fixative at $40^{\circ} \mathrm{C}$ for at least 12 hours. The brain was removed from the skull and immersion fixed in FAM for 24 hours before being transferred to a $70 \%$ solution of methanol.

\section{Quantitation of ischaemic brain damage}

After detaching the hindbrain, the forebrain was cut into four equally spaced coronal blocks that were processed, embedded in paraffin wax and sectioned at multiple levels (about 100 sections per brain). The sections were stained alternatively by haematoxylin and eosin and a method combining cresyl violet and Luxol fast blue and were examined by conventional light microscopy by two of us (KAO and DIG) independently without knowledge of experimental protocol.

Areas of early infarction ${ }^{14}$ were delineated on paraffin sections at preselected stereotactically determined coronal levels and transcribed on to scale diagrams ( $\times 4$ actual size) of forebrain drawn from the Atlas of Konig and Klippel. ${ }^{15}$
Quantitation was initially carried out at 17 coronal levels, the anterior co-ordinates of which are given in table 1 .

After suitable validation (see Results) area measurements were carried out routinely at eight coronal levels, viz those indicated by anatomical location in table 1 , fig 1 . The image analyser function of the Quantimet 720 was used to obtain area measurements. Area was expressed as pixels; the linear magnification factor was $5 \cdot 5$, equivalent to 360 pixels per $\mathrm{mm}^{2}$. Using this method, area measurements of normal hemisphere, cortex and neostriatum and of ischaemic damage in the same regions were obtained. An approximation to total volume of ischaemic damage was achieved by integration of areas with the distance between each level. The end points for integration for cortex and hemisphere were anterior 12.5 and posterior 0.05 . The amount of ischaemic damage was expressed both as a percentage of the hemisphere, cortex and neostriatum, and in absolute terms $\left(\mathrm{mm}^{3}\right)$.

\section{Statistical analysis}

For comparison between the controls and the other groups of animals, unpaired Student's $t$ test was used.

\section{Results .}

\section{Cardiovascular and respiratory status}

These are given in table 2. Apart from mean arterial blood pressure during induced hypotension (fig 2), there were no statistically significant differences between any of the physiological parameters in the various groups of animals.

\section{Neuropathology}

All the specimens were judged to be well perfusion ; fixed as shown by the absence of intravascular blood, good neuronal morphology and the lack of the cytological artefacts "dark cell" and "hydropic cell". ${ }^{1617}$ The lesions appeared as areas of early infarction ${ }^{14}$ within the territory of the occluded MCA, that is in the dorso-lateral cortex and in the lateral portion of

Table 1 List of 17 coronal levels of rat forebrain and their anterior co-ordinates

\begin{tabular}{llc}
\hline Anatomical landmark & Level & Co-ordinate $(\mathbf{m m})$ \\
\hline Olfactory tract & 1 & $10 \cdot 50$ \\
Nucleus accumbens & $1 \mathrm{~A}$ & 9.82 \\
& 2 & 8.92 \\
Septal nuclei & $2 \mathrm{~A}$ & 7.89 \\
Globus pallidus & 3 & 7.19 \\
Anterior hypothalamus & $3 \mathrm{~A}$ & 6.67 \\
Lateral habenula & $4 \mathrm{~A}$ & 6.06 \\
Medial geniculate & 5 & 5.78 \\
Aqueduct & $6 \mathrm{~A}$ & 5.15 \\
& $6 \mathrm{~A}$ & 3.38 \\
& 7 & 2.97 \\
& $7 \mathrm{~A}$ & 2.18 \\
& 8 & 1.61 \\
& $8 \mathrm{~A}$ & 1.02 \\
\hline
\end{tabular}



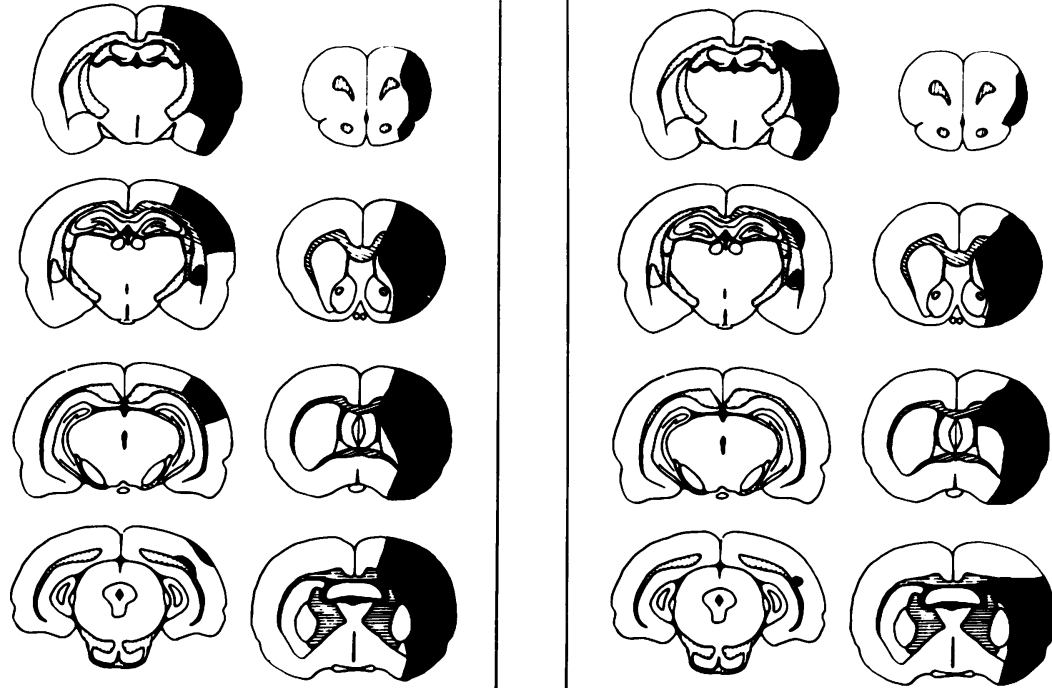

Fig 1 Upper left; normotensive animal with largest lesion ( $2 \dot{4} \cdot 6 \%$ of hemisphere with ischaemic brain damage). Upper right; normotensive animal with smallest amount of ischaemic brain damage (11.4\% of the hemisphere). Lower left; hypotensive animal with largest lesion $(35.2 \%$ of hemisphere with ischaemic brain damage). Lower right; hypotensive animal with smallest amount of ischaemic brain damage (23.6\% of hemisphere with ischaemic brain damage). For group means, see table 2. 
Table 2 Physiological variables at occlusion of the middle cerebral artery and amount of ischaemic brain damage in the normotensive and hypotensive groups of animals

\begin{tabular}{|c|c|c|c|c|}
\hline & & Normotensive $(n=9)$ & \multicolumn{2}{|c|}{ Hypotensive ( $n=7$ ) } \\
\hline $\begin{array}{l}\text { Temperature }\left({ }^{\circ} \mathrm{C}\right) \\
\text { Mean arterial blood pressure }(\mathrm{mm} \mathrm{Hg})\end{array}$ & & $\begin{array}{r}37 \pm 1 \\
108 \pm 3\end{array}$ & \multirow{2}{*}{\multicolumn{2}{|c|}{$\begin{array}{c}37 \pm 1 \\
100 \pm 3 \\
60 \pm 2 \\
37 \pm 1 \\
138 \pm 4 \\
7 \cdot 5 \pm 0 \cdot 01 \\
10 \pm 1\end{array}$}} \\
\hline $\begin{array}{l}\mathrm{PaCO}_{2}(\mathrm{~mm} \mathrm{Hg}) \\
\mathrm{PaO}_{2}(\mathrm{~mm} \mathrm{Hg}) \\
\mathrm{pHa} \\
\text { Glucose }(\mathrm{mM})\end{array}$ & & $\begin{array}{l}34 \pm 1 \\
100 \pm 7 \\
7 \cdot 4 \pm 0.02 \\
10 \pm 1\end{array}$ & & \\
\hline $\begin{array}{l}\text { Ischaemic brain damage in: } \\
\text { Hemisphere } \\
\text { Cortex } \\
\text { Neostriatum } \\
\text { Mean } \pm \mathrm{SE}\end{array}$ & $\begin{array}{l}\mathrm{mm}^{3} \\
84 \pm 5 \\
52 \pm 4 \\
21 \pm 1\end{array}$ & $\begin{array}{l}\% \\
20 \pm 1 \\
27 \pm 2 \\
72 \pm 4\end{array}$ & $\begin{array}{l}\mathrm{mm}^{3} \\
120 \pm 7 \\
84 \pm 6 \\
24 \pm 1\end{array}$ & $\begin{array}{l}\% \\
29 \pm 2 \\
45 \pm 3 \\
83 \pm 3\end{array}$ \\
\hline
\end{tabular}

*MABP was reduced to $60 \pm 2 \mathrm{~mm} \mathrm{Hg} 20 \mathrm{~min}$ after occlusion of the MCA for 30 min before restoration to baseline levels.

the neostriatum. The boundaries between areas of infarction and adjacent normal brain could be sharply delineated. Neuropathological abnormalities were not found in any other part of the brain.

\section{Statistical validation}

All microscopy and area measurements were carried out "blind" without prior knowledge of the experimental protocol.

Investigations were undertaken to determine the number of stereotactic levels from which the amount of infarction could be measured accurately. Of course the greatest degree of accuracy would be achieved by calculating the volume of structural damage after serially sectioning the forebrain. As this is not feasible routinely, the volume of damage was initially assessed from 17 levels approximately $0.6 \mathrm{~mm}$ apart, selected from about 100 stained histological sections. This was

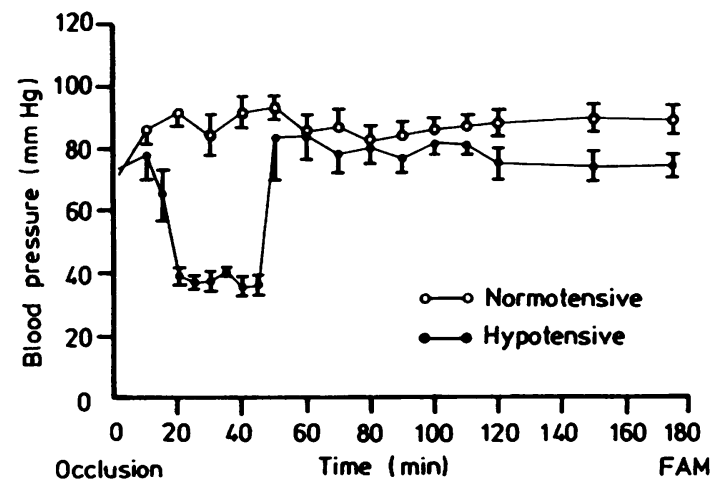

Fig 2 Mean arterial blood pressure in the post-operative period in normotensive animals and in animals subjected to transient hypotension. The MCA was occluded at time zero and the animals killed by perfusion fixation with FAM at least 180 minutes after occlusion. Data are presented as mean $\pm S E M$. compared with volumes of damage calculated from area measurements at 8 stereotactic levels in the same animals. The calculated volumes were indistinguishable (mean difference $\pm \mathrm{SD} ; 0.06+1.3 \mathrm{~mm}^{3} \mathrm{n}=9$, fig 3 ). The volume was also calculated from 7,5 and 3 stereotactic levels but in each case this was associated with an increase in variance and deviation from the true volumes (based on 17 levels). For example, the use of 3 levels significantly ( $p<0.01$ ) overestimates the volume of damage in a highly variable manner (mean difference $7.8 \pm 5.2 \mathrm{~mm}^{3}$, fig 4). Based on these results, the amount of infarction was calculated from 8 levels.

The intra-observer reproducibility of volumetric assessment on two separate occasions was excellent (product moment coefficient of correlation; $=0.995$, $\mathrm{n}=18$; the mean difference \pm SD on the two occasions was $1 \cdot 1 \pm 3.6 \%$ of brain area, fig 5). Thus the potential errors resulting from selection of the sections at the appropriate stereotactic level, microscopic evaluation of the ischaemic damage, transcription to

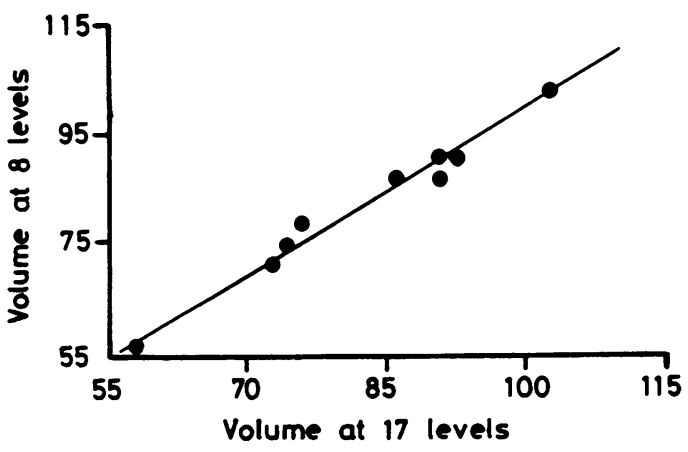

Fig 3 Comparison of the hemisphere volume $\left(\mathrm{mm}^{3}\right)$ derived from area assessments at 8 and 17 stereotactic levels. The correlation is excellent (coefficient of correlation $)^{2}=99 \cdot 1$. 


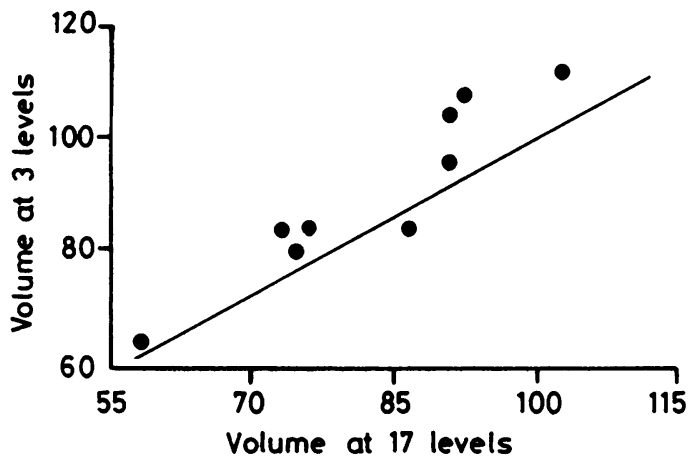

Fig 4 Comparison of the hemispheric volume $\left(\mathrm{mm}^{3}\right)$ derived from area measurements at 3 and 17 stereotactic levels. The correlation between the two calculated volumes is less well maintained (coefficient of correlation $)^{2}=89 \cdot 0$.

the scale drawings and area assessment on the image analyser, all of which are included in the assessment of reproducibility, are minimal.

\section{Influence of hypotension}

There was a highly significant increase in the volume of infarction (table 2$)$ in both the hemisphere $(p<$ $0.01)$ and cortex $(p<0.001)$ of the hypotensive animals compared with the normotensive animals. The distribution of the areas of ischaemic damage in the cortex is shown in fig 6 , from which it can be seen that the area of damage is greater at each stereotactic level

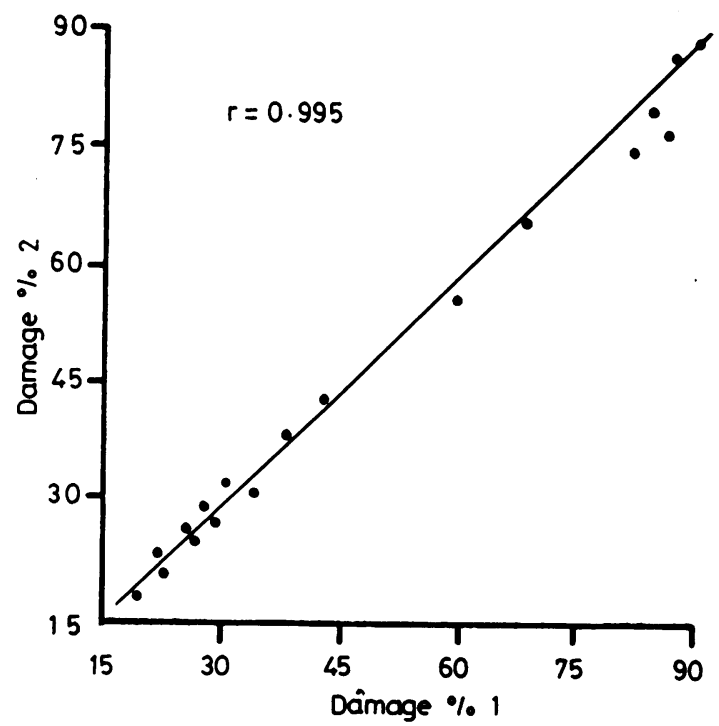

Fig 5 The inter-observer variation in assessment of volume on two separate occasions was excellent (coefficient of (correlation $)^{2}=99 \cdot 0$.

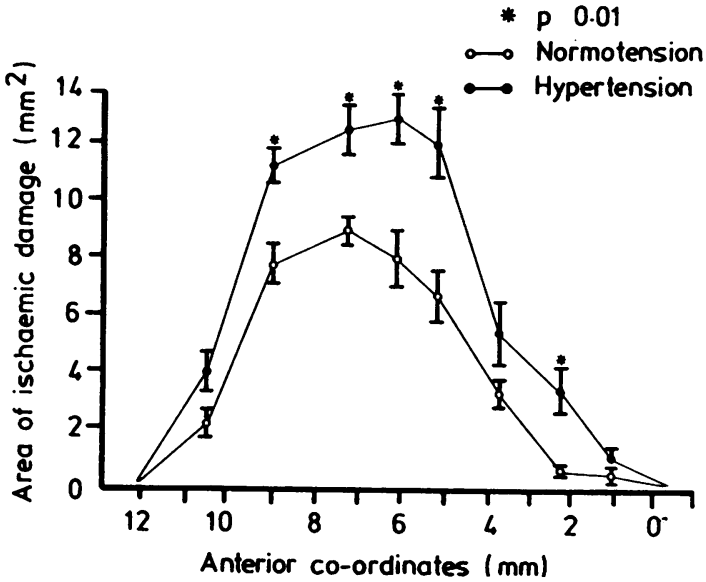

Fig 6 Influence of transient hypotension on the areas of ischaemic damage in the cerebral cortex at various stereotactic levels. Significant increases $(p<0 \cdot 1)$ are seen after hypotension at levels 2, 3, 4, 5 and 7 (for co-ordinates see table 1).

in the hypotensive than in the normotensive animals but the changes are least pronounced at the most rostral level (level 1) and at the level of the habenula (level 6). The distribution of damage in the cerebral hemisphere at different stereotactic levels was similar to that of cortex, which of course comprises a majoro portion of the hemisphere. There was no statistical? difference between normotensive and hypotensive animals in the volume of the ischaemic lesions in the neostriatum nor in the areas of neostriatum damage at each stereotactic level (fig 7).

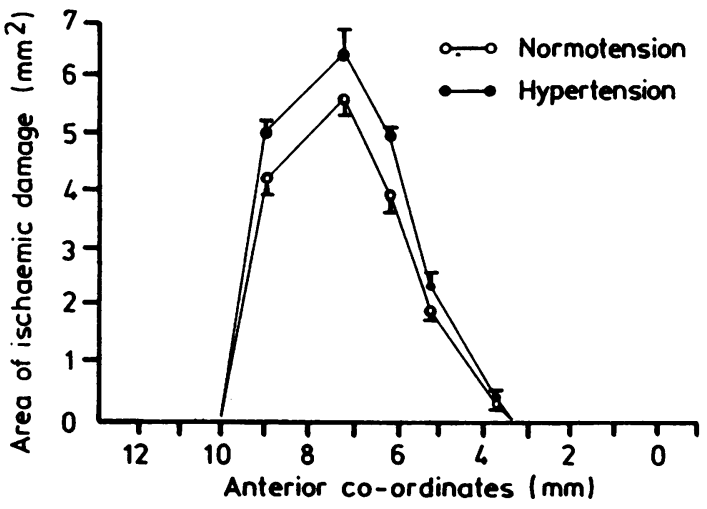

Fig 7 Influence of transient hypotension on the area of ischaemic damage in the neostriatum at various stereotactic levels. There are no significant increases with hypotension in any of the 5 levels assessed. 


\section{Discussion}

\section{The model and operative technique}

The intracranial occlusion of the MCA in the rat is a useful model of focal cerebral ischaemia for several reasons: these include the close similarities between the anatomy of the cranial circulations of rat and man, ${ }^{18}$ the detailed information that exists for the rat brain concerning the anatomical organisation of neurotransmitter systems and their neuropharmacology ${ }^{19-22}$ and the extensive use made of the rat in the range of quantitative autoradiographic methods that have been developed to assess dynamic aspects of cerebrovascular function (for example blood flow, glucose use, protein synthesis, $\mathrm{pH}$, permeability of the blood-brain barrier).

The development of a reproducible model of focal infarction in the rodent has proved difficult. After an extracranial artery is occluded the efficiency of the intracranial collateral circulation usually prevents the development of brain damage unless an additional insult, such as hypoxia, ${ }^{23-26}$ or hypotension, ${ }^{27-29}$ is added or when a pre-existing vascular anomaly ${ }^{30-33}$ or diffuse vascular disease is present. ${ }^{34}$ These additional insults introduce important complicating factors and the resulting lesions are often variable.

Intracranial occlusion of the MCA is used widely to produce focal ischaemia in large animals, such as the cat, ${ }^{25} \operatorname{dog}^{35}$ and non-human primate. ${ }^{136}$ Provided the artery is occluded proximally and the cardiovascular and respiratory status of the animal are controlled rigorously, then a reproducible lesion results. These generalisations are also true in the rat model of focal cerebral infarction developed in our laboratory. ${ }^{712}$ In our animals, the area damaged invariably includes the cortex of the frontal lobe and the lateral part of the neostriatum. With increasing experience it has become apparent that relatively minor differences in operative technique affects significantly the circulatory and structural consequences of occlusion of the MCA in our rat model. This depends in part on whether or not the lenticulo-striate arteries are included in the procedure, and in part upon good microsurgical technique, well controlled anaesthesia and close physiological monitoring. As shown in table 2 , consistency in the amount of infarction can be achieved within a group of animals subjected to the same procedures (for example the coefficient of variation for ischaemic damage in the cerebral hemisphere is less than $20 \%$ ). However, even in our laboratory a single neurosurgical operator carries out the procedure in all animals, contemporaneous untreated (control) animals are randomised with treated (experimental) animals - both from the same supplier in an attempt to achieve a homogeneous population of animals, and fixed limits of physiological variables are maintained. We believe that these are important because slight differences in operative technique produce lesions of different size in the cortex (contrast present study with Mohamed ${ }^{36}$ from the same laboratory), there is clear evidence that the strain of rat can influence the volume of infarction after occlusion of the $\mathrm{MCA},{ }^{37}$ and there is good evidence from the present study that the size of the cortical lesion increased by more than $50 \%$ when the systemic blood pressure was reduced by $50 \mathrm{~mm} \mathrm{Hg}$. The variability between the different groups of control animals is of little consequence, as it is the comparison between the control and the experimental animals that determines the statistical significance or otherwise of the experimental procedure in well designated studies.

\section{Objective assessment of early infarction}

There have been numerous and varied attempts at assessing the severity of ischaemic brain damage. For example, in models of diffuse cerebral ischaemia in which the histological end point is selective neuronal necrosis, grades of injury have been derived that either reflect the number of damaged neurons. ${ }^{23333839}$ or provide an actual count of the number of necrotic neurons..$^{40}$ On the other hand, in models of focal cerebral ischaemia, the size of the lesion delineated macroscopically several days after occlusion of a MCA has been employed widely. ${ }^{54142}$ The amount of chronically infarcted tissue has been determined by estimating the average end-area from photographs of brain slices, ${ }^{5}$ or by a grid system..$^{4243}$ More objective methods, again in animals surviving for a number of days, include cross sectional planimetry using a millimetre grid on histological sections, ${ }^{44}$ a combination of volume displacement of brain slices and polar planimetry of photographs of histological sections from these slices made to the same scale, ${ }^{4546}$ and the weighing of areas of damage cut from diagrams. ${ }^{47}$ Other methods have included an assessment of the amount of ischaemic damage at either a few stereotactically determined "representative" sections, ${ }^{48}$ or many stereotactically determined levels of the brain. ${ }^{374950}$ Recently a method has been described $^{51}$ that measures infarct size computed from photography of dorsal and lateral surfaces of the brain. The availability of low cost image analysis systems now permits irregular area measurements with excellent reproducibility. The introduction of such systems will undoubtedly replace the previous cumbersome methods of quantitation.

The unique advantage of the method described in this paper is that the amount of infarction has been determined in acute experiments. Unlike all chronic models of cerebral infarction, key physiological variables, such as systemic arterial blood pressure and blood gas status, have been monitored throughout 
the entire post-operative period. Moreover, whereas in models of chronic infarction attempts have been made to quantify hemispheric damage alone, in the system described here separate volumes of ischaemic damage are derived for the hemisphere, cortex and the neostriatum. As already noted in the present study, hypotension only increased the volume of infarction in the cerebral cortex and did not lead to a significant increase in structural damage in the neostriatum. Assessment of the area of infarction at predetermined stereotactic levels defines the distribution of the ischaemic damage, the pattern of which is influenced differentially by various treatments. For example, hypotension increases the area of ischaemic damage in the cortex in the central distribution of the territory of the MCA, whereas nimodipine reduces the area of structural damage only at the periphery of the territory of the middle cerebral artery. ${ }^{36}$

The model has a number of limitations and constraints. These include the use of skilled microsurgical techniques, and the need for experienced technicians to cut good quality sections at multiple levels of the forebrain of the animals. This latter task takes 1-2 hours of cutting and coding the material and a further 2 hours for mounting, staining, and labelling prior to histological assessment. Once the sections have been prepared, it is necessary to establish which sections are the best match to the predetermined stereotactic levels for which a dissecting microscope is employed. After the appropriate sections have been identified, they are examined by conventional light microscopy to identify any ischaemic damage and to delineate its boundaries both on the slides and on the anatomical line diagrams. This stage is particularly important as the observer requires knowledge of the histological appearances of early infarction, ${ }^{14}$ and its separation from the dark cell artefact. ${ }^{1617}$ These skills can be readily acquired with appropriate training. Even so, the boundaries of the focal lesion are discernible only with certainty if the animals are allowed to survive 3-4 hours post-occlusion, are killed by perfusion fixation and the specimens are processed in a suitable manner.

\section{Validation of the method of quantification}

In all our studies the paraffin sections were assessed "blind" by two observers, who at no stage knew to which group the specimens had been allocated

If the method of quantification was to be useful generally, it required to be reproducible, practical and sufficiently sensitive to identify both an increase and a decrease in lesion size in response to various procedures. We found that the assessment of the amount of ischaemic damage on separate occasions by the same individual is highly reproducible. Reproducibility between different individuals in identifying the ischaemic damage by light microscopy is similarly excellent. In the methods of quantification advocated hitherto, reproducibility has rarely been tested critically.

Further requisites were that the method should not involve an undue amount of technical work, or require that an experienced microscopist spend many hours examining the histological slides. Initially it was considered that the forebrain would have to be examined at either 32 or 17 levels. In fact it has been possible to show that the minimum number of levels at which the assessment can be made is 8 levels without loss of accuracy. A volumetric assessment based on fewer levels results in considerable increase in interanimal variability and decreased accuracy in the volume which is derived.

The system of quantitation described here can determine both increases and decreases in the amount of infarction with different treatments. For example, it has been possible to establish an increase in lesion size after a transient period of hypotension $(60 \mathrm{~mm} \mathrm{Hg}$ for $30 \mathrm{mins})$ in the cortex with minimal changes in the neostriatum. These findings are consistent with the extensive collateral circulation in the cortex through the pial arteries at normotension, whereas the lenticulo-striate arteries supplying the neostriatum are effectively end arteries. ${ }^{1852} 53$

Two previous attempts have been made towards quantifying the amount of infarction which results ion the rat from occlusion of the MCA, though at a more distal site than the present study. ${ }^{5154}$ In both studies? with their long post-operative survival, the interanimal variability in the amount of ischaemic damage was considerable. For example, the lesions described by Robinson and Coyle ${ }^{54}$ had a diameter between 1 and $5 \mathrm{~mm}$, and the area of infarction measured by Coyle $e \mathrm{al}^{51}$ had a coefficient of variation of $40 \%$ even after elimination of non-infarcted animals. In the present study the low coefficient of variation of about $20 \%$ allows the use of considerably smaller groups of experimental animals.

The method described here can identify the more subtle changes in the amount of ischaemic brain damage which occur with treatment with the calcium antagonist, nimodipine. ${ }^{3655}$ In animals pretreated with nimodipine prior to occlusion of the MCA there was a reduction in the volume of infarction in the rostral part of the cortex but not in the neostriatum. ${ }^{36}$ In contrast, the administration of nimodipine after occlusion of the MCA did not significantly alter the amount of infarction at any of the 8 predetermined stereotactic levels selected for quantification. ${ }^{55}$

\section{Conclusion}

There are many animal models to evaluate the 
putative anti-ischaemic effects of pharmacological agents, ${ }^{5657}$ but rarely has it been possible to make confident statements about the size of the lesion when comparing untreated and drug treated animals. In this paper a method is described which measures accurately the volume of early cerebral infarction in the rat following occlusion of a middle cerebral artery. The reproducibility of this method allows objective investigation of the beneficial and detrimental effects of various influences upon the volume of early ischaemic brain damage.

These studies were supported by grants from the Medical Research Council and the Wellcome Trust. It is a pleasure to thank ET MacKenzie, B Gotti and Audrey Lawrence for advice and encouragement, the technical staff at the Wellcome Surgical Institute and the Department of Neuropathology for their skilled assistance, the Department of Medical Illustration, Southern General Hospital, for photographic assistance and Mrs J Rubython for typing the manuscript.

\section{References}

1 Crowell RM, Olsson Y, Klatzo I, et al. Temporary occlusion of the middle cerebral artery in the monkey: clinical and pathological observations. Stroke 1970; 1:439-48.

2 Hayakawa T, Waltz AG. Intracranial pressure, blood pressure and pulse rate after occlusion of a middle cerebral artery in cats. $J$ Neurosurg 1975;43:399-407.

3 Hudgins WR, Garcia JH. Transorbital approach to the middle cerebral artery of the squirrel monkey: a technique for experimental cerebral infarction applicable to ultrastructural studies. Stroke 1970;1:107-11.

4 Molinari GF, Laurent JP. A classification of experimental models of brain ischemia. Stroke 1976;7:14-17.

5 Sundt TM, Waltz AG. Experimental cerebral infarction in retro-orbital, extradural approach for occluding the middle cerebral artery. Mayo Clin Proc 1966;41: 159-68.

6 Symon L, Pasztor E, Branston NM. The distribution and density of reduced cerebral blood flow following acute middle cerebral artery occlusion: an experimental study by the technique of hydrogen clearance in baboons. Stroke 1974;5:355-64.

7 Tamura A, Graham DI, McCulloch J, et al. Focal cerebral ischaemia in the rat. I. Description of technique and early neuropathological consequences following middle cerebral artery occlusion. J Cereb Blood Flow Metab 1981;1:53-60.

8 Tamura A, Graham DI, McCulloch J, et al. Focal cerebral ischaemia in the rat. II. Regional cerebral blood flow determined by $\left[{ }^{14} \mathrm{C}\right]$ iodoantipyrine autoradiography following middle cerebral artery occlusion. J Cereb Blood Flow Metab 1981;1:61-9.

9 Tyson GW, Teasdale GM, Graham DI, et al. Cerebrovascular permeability following MCA occlusion in the rat. $J$ Neurosurg 1982;57:186-96.

10 Tyson GW, Teasdale GM, Graham DI, et al. Focal cerebral ischemia in the rat: topography of hemodynamic and histopathological changes. Ann Neurol 1984;15:559-67.

11 Graham DI, Osborne KA, Shigeno T, et al. Ischaemic brain damage - a quantitative approach. J Cereb Blood Flow Metab 1985;5(Suppl 1):S383-4.

12 Shigeno T, McCulloch J, Graham DI, et al. Pure cortical ischemia versus striatal ischemia. Circulatory, metabolic and neuropathological consequences. Surg Neurol 1985;24:47-51.

13 Hernandez MJ, Brennan RW, Bowman GS. Cerebral blood flow autoregulation in the rat. Stroke 1978;9:150-5.

14 Brierley JB, Graham DI. Hypoxia and vascular disorders of the central nervous system. In: Adams JH, Corsellis JAN, Duchen LW, eds. Greenfield's Neuropathology. 4th ed. London: Edward Arnold, 1984:125-207.

15 Konig JFR, Klippel RA. The Rat Brain: a Stereotaxic Atlas of the Forebrain and Lower Parts of the Brain Stem. New York: Krieger, 1963.

16 Brown AW. Structural abnormalities in neurones. J Clin Pathol 30, Suppl (Roy Coll Path) 1977;11:155-69.

17 Cammermeyer J. The importance of avoiding "dark" neurons in experimental neuropathology. Acta Neuropathol (Berl) 1961;1:245-70.

18 Yamori $\mathrm{Y}$, Horie $\mathrm{R}$, Handa $\mathrm{H}$, et al. Pathogenetic similarity of strokes in stroke-prone spontaneously hypertensive rats and humans. Stroke 1976;7:46-53.

19 Brown K, Cooper SJ. Chemical Influences on Behaviour. London: Academic Press, 1979.

20 Iversen LL, Iversen SD, Snyder SH. Handbook of Psychopharmacology. Vol 9. Chemical pathways in the brain. London: Plenum Press, 1978.

21 Roberts PJ, Woodruff GN, Iversen LL, eds. Advances in Biochemical Psychopharmacology. Vol 19. Dopamine. New York: Raven Press, 1978.

22 Siesjö BK. Brain Energy Metabolism. Chichester: John Wiley, 1978.

23 Brown AW, Brierley JB. The nature, distribution and earliest stages of anoxic-ischaemic nerve cell damage in the rat brain as defined by the optical microscope. Br J Exp Pathol 1968;49:87-106.

24 Levine S. Anoxic-ischemic encephalopathy in rats. Am J Pathol 1960;36:1-17.

25 Salford LG, Plum F, Brierley JB. Graded hypoxiaoligemia in rat brain. Arch Neurol 1973;29:227-33.

26 Salford LG, Plum F, Brierley JB. Graded hypoxiaoligemia in rat brain. Arch Neurol 1973;29:234-8.

27 Eklof B, Siesjö B. The effect of bilateral carotid ligation upon the blood flow and energy state of the rat brain. Acta Physiol Scand 1972;86:155-65.

28 Mendelow AD, Graham DI, McCulloch J, et al. The distribution of ischemic damage and cerebral blood flow after unilateral carotid occlusion and hypotension in the rat. Stroke 1984;15:704-10.

29 Nordstrom C-H, Siesjö BK. Effects of phenobarbital in cerebral ischemia. Part I. Cerebral energy metabolism during pronounced incomplete ischemia. Stroke 1978;9:327-35.

30 Ito U, Spatz M, Walker JT, et al. Experimental cerebral 
ischemia: Mongolian gerbils. I. Light microscopic observations. Acta Neuropathol (Berl) 1975;32: 209-23.

$31 \mathrm{Kahn} \mathrm{K}$. The natural course of experimental cerebral infarction in the gerbil. Neurology 1972;22:510-5.

32 Levine S, Payan H. Effects of ischemia and other procedures in the brain and retina of the gerbil (Meriones unguiculatus). Exp Neurol 1966;16:255-62.

33 Levy DE, Brierley JB, Plum F. Ischaemic brain damage in the gerbil in the absence of "no-reflow". $J$ Neurol Neurosurg Psychiatry 1975;38:1197-205.

34 Okamoto K, Aoki K. Development of a strain of spontaneously hypertensive rats. Jpn Circ J 1983;27:282-93.

35 Suzuki J, Yoshimoto T, Tanaka S, et al. Production of various models of cerebral infarction in the dog by means of occlusion of intracranial trunk arteries. Stroke 1980;11:337-41.

36 Mohamed AA, Gotoh O, Graham DI, et al. Effect of pretreatment with the calcium antagonist Nimodipine on local cerebral blood flow and histopathology after middle cerebral artery occlusion. Ann Neurol 1985;4:705.

37 Duverger D, Le Coffre C, MacKenzie ET. Histological quantification of cerebral infarction following middle cerebral artery occlusion in various rat strains. J Cereb Blood Flow Metab 1985;5(Suppl 1):S415-6.

38 Ginsberg MD, Graham DI, Welsh FA, et al. Diffuse cerebral ischemia in the cat: III. Neuropathological sequelae of severe ischemia. Ann Neurol 1979;5: 350-8.

39 Pulsinelli WA, Brierley JB, Plum F. Temporal profile of neuronal damage in a model of transient forebrain ischemia. Ann Neurol 1982;11:491-8.

40 Smith M-L, Auer RN, Siesjö BK. The density and distribution of ischemic brain injury in the rat following 2-10 min of forebrain ischemia. Acta Neuropathol (Berl) 1984;64:319-32.

41 Michenfelder JD, Milde JH, Sundt TM. Cerebral protection by barbiturate anesthesia: use after middle cerebral artery occlusion in Java monkeys. Arch Neurol 1976;33:345-50.

42 Smith AL, Hoff JT, Nielsen SL, et al. Barbiturate protection in acute focal cerebral ischemia. Stroke 1974;5:1-7.

43 Hoff JT, Smith AL, Hankinson HL, et al. Barbiturate protection from cerebral infarction in primates. Stroke 1975;6:28-33.

44 Moseley JI, Laurent JP, Molinari GF. Barbiturate atten- uation of the clinical course and pathologic lesions in a primate stroke model. Neurology 1975;25:870-4.

45 Black KL, Weidler DJ, Jallad NS, et al. Delayed pentobarbital therapy of acute focal cerebral ischemia. Stroke 1978;9:245-9.

46 Bose B, Osterholm J, Berry R. A reproducible experimental model of focal cerebral ischemia in the rat. Brain Res 1984;311:385-91.

47 Hayakawa T, Waltz AG, Jacobson RL. Hypertension and acute focal cerebral ischemia. Infarction and edema after occlusion of a middle cerebral artery in cats. Stroke 1979;10:263-7.

48 Tamura A, Asano T, Sano K, et al. Protection from cerebral ischemia by a new Imidazole derivative (Y-9179) and pentobarbitol. A comparative study in chronic middle cerebral artery occlusion in cats. Stroke 1979;10:126-34.

49 Delage I, Duverger D, Gotti R, et al. Correlation of local blood flow, glucose consumption and probability of necrosis following a middle cerebral artery occlusion in the rat. Eur Neurol 1981;20:258-64.

50 Gotti B, MacKenzie ET, Young AR. The pharmacotherapy of focal cerebral ischemia - development of an experimental model. $J$ Chron Dis Ther Res 1984;8:44-61.

51 Coyle P, Odenheimer DJ, Sing CF. Cerebral infarction after middle cerebral artery occlusion in prognosis of spontaneously stroke-prone and normal rats. Stroke 1984;15:711-6.

52 Coyle P, Jokelainen PT. Dorsal cerebral arterial collaterals of the rat. Anat Rec 1982;203:397-404.

53 Rieke GK, Bowers DE, Penn P. Vascular supply patterm to rat caudatoputamen and globus pallidus: scannings electron microscopic study of vascular endocasts of stroke-prone vessels. Stroke 1981;12:840-7.

54 Robinson RG, Coyle JT. The differential effect of right versus left hemispheric cerebral infarction on catecholamines and behaviour in the rat. Brain Res 1980;188:63-78.

55 Gotoh O, Mohamed AA, McCulloch J, et al. Nimodipine and the hemodynamic and histopathological consequences of middle cerebral artery occlusion in the rat. J Cereb Blood Flow Metab 1986;6:321-31.

56 Hossmann K-A. Treatment of experimental cerebral ischemia. J Cereb Blood Flow Metab 1982;2:275-97.

57 Wiedemann K, Hoyer S, eds. Brain Protection. Morphological, Pathophysiological and Clinical Aspects Berlin: Springer-Verlag, 1983. 